\title{
AN OVERVIEW ON CLOUD COMPUTING
}

\author{
Mr. Mohit Bhayana \\ B.Tech Student \\ Department of CSE \\ Arya College of Engineering \& Research Centre \\ Jaipur, Rajasthan \\ Mr. Pradeep Jha \\ Assistant Professor \\ Department of CSE \\ Arya College of Engineering \& Research Centre \\ Jaipur, Rajasthan
}

\begin{abstract}
This paper gives information about cloud computing and the benefits of using a cloud and cloud service. Now the question arises what is the cloud? The answer is that it is a platform where one can store their data and can access all the services provided without actually having real hardware via virtualization through cloud vendors.
\end{abstract}

Keywords: Cloud vendors, types of cloud, virtualization.

\section{INTRODUCTION}

In today's generation, cloud technology increases day by day. But what exactly is the cloud? And why cloud? The answer is that the cloud is the biggest platform where you can access the services provided and can store your data. Cloud computing is a technology that keeps up data and its application by using the internet and central remote servers [1]. "Cloud" is a set of hardware and software that together deliver many aspects of computing as online services. Using cloud users can access files from any device that has internet. Cloud provides better accessibility to user's data from any device. It assures $100 \%$ security to the data which is stored on the server. Today, many companies are switching themselves to cloud infrastructure as it saves the cost, value of time, maintenance of web applications and other business-oriented programs, etc. Without the cloud, it would be very difficult manage the business-oriented programs, web site hosting, application maintenance, etc. It has four types of cloud models public cloud, private cloud, community cloud, and hybrid cloud. Cloud computing is a distributed computing paradigm to provides customers with demand computing services. Cloud consists of physical machines on its data centers. Then virtualization is provided on these data centers. Virtualization is a key aspect of cloud computing. Cloud computing architecture addresses various difficulties of data preprocessing. Using virtualization virtual machines are created which are then provided to the end-users.

\author{
Ms. Komal Kriplani \\ B.Tech Student \\ Department of CSE \\ Arya College of Engineering \& Research Centre, \\ Jaipur, Rajasthan \\ Ms. Somya Sharma \\ Assistant Professor \\ Department of CSE \\ Arya College of Engineering \& Research Centre \\ Jaipur, Rajasthan
}

Types of cloud models:

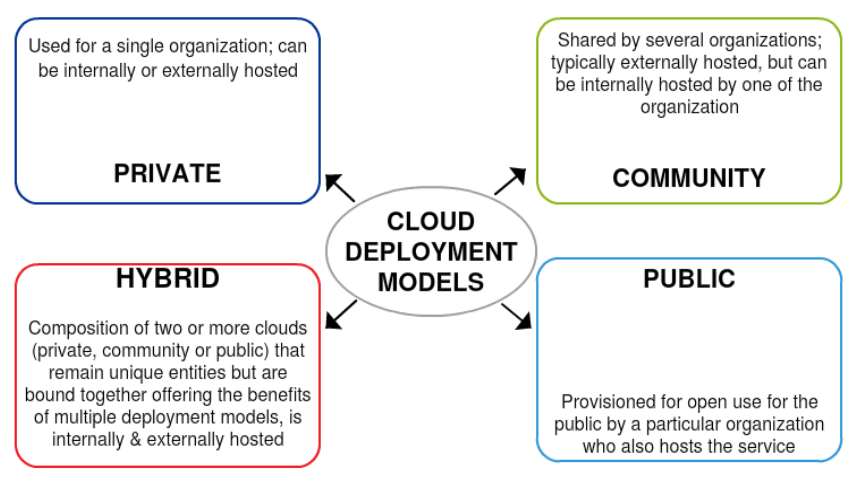

Fig -1: Types of cloud models

1. Private cloud - The cloud in this model is operated by an individual and it is non-shareable to any other personality.

2. Community cloud - The cloud infrastructure is shared by several organizations or a group of people have shared concerns.

3. Public cloud - The cloud infrastructure and services are made available to the general public and can be used by anyone.

4. Hybrid cloud - The cloud in this model is a mixture of two or three cloud models and together it provides extra benefits as it is made up of two different cloud models.

\section{ADVANTAGE}

- Reduced investment when we need to host a web site then we need resources to host the website then client will directly request to cloud vendors for rent the resources at the time of hosting. It will help to save the investment 


\section{International Journal of Engineering Applied Sciences and Technology, 2020 \\ Vol. 4, Issue 12, ISSN No. 2455-2143, Pages 290-292 \\ Published Online April 2020 in IJEAST (http://www.ijeast.com)}

cost, time, extra efforts, and help to arise the business value.

- Increased scalability It help to manage the scale up and scale down at the time of cloud resources usage by clients.

- Increased availability and Reliability all the services \& resources 24/7 available for clients when they want to use and system is always reliable it helps to recover from any system failure or conflict [2].

- The cloud is pay per use model i.e. the user has to pay only for the services that they are using.

- Virtualization technology gives the user the illusion that they are having all the resources available.

- Cloud provides mobility to its users which means that user can access its services on any device which has internet connectivity. The user just has to login to his/her account and then he/she can use all the services.

- Once the data is stored on the cloud then backup and restoration of that data are very easy.

- Using the cloud services user get access to unlimited storage capacity and at any point in time, you can expand your storage by paying the fees.

- Cloud also offers advanced data security which ensures that your data on the cloud is secure from any threats.

\section{DISADVANTAGES}

- Data privacy is one of the major concerns while migrating into the cloud. Data is stored on the servers which can be easily hacked by the third person.

- The major disadvantage of using the cloud is its security issues i.e. the data stored on the cloud is not secure as it can be easily attacked.

- Data backup should be done continuously as any downtime can result in the loss of important data.

\section{NEED OF CLOUD COMPUTING}

One question comes into our minds why cloud? So, the answer is that anyone who wants low-cost services at the same time having high-end resources will eventually need cloud services. There are certain reasons why we need a cloud. Some of them are

- Cloud provides mobility which is essential for a person as we cannot carry our system everywhere.

- Cloud provides an infrastructure for enhancing the business process.

- Reduced maintenance costs as it is being handled by service providers.

- Cloud provides better asset utilization i.e. when company $\mathrm{A}$ is not using any particular resource than it is made available to any other company which requires that resource.

\section{FUTURE OF CLOUD COMPUTING}

The future of cloud holds a promising future of business as in the coming year's cloud will provide organizations what they want on-demand easily. Researchers predict that in the future $90 \%$ of the population will be using cloud services in their day to day life. Cloud computing is accelerating globally and there is no doubt that the cloud is going to become a new trend in the market. It is predicted that most of the applications will be built only for the cloud. Enterprises are increasingly relying on the cloud for their individual development and manage supply chains. Cloud has overcome the difficulties of handling hardware.

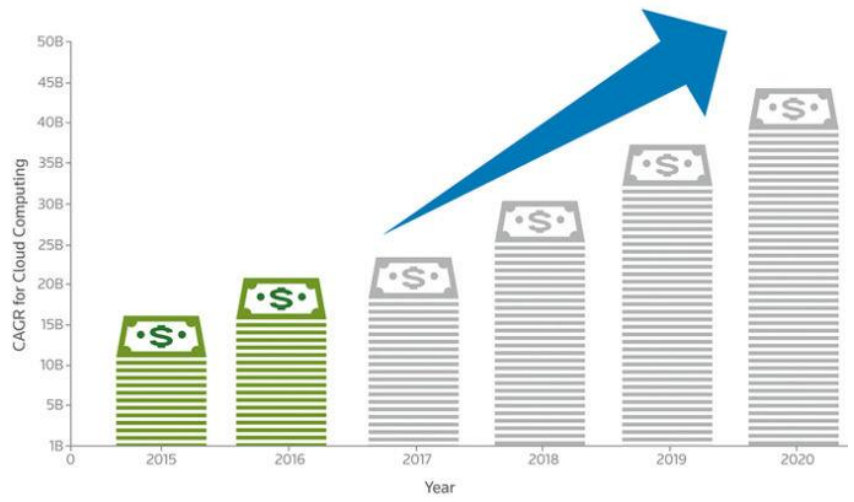

Fig -2: Growth in cloud computing

(c)

(d)

\section{CONCLUSION}

In this paper, we tend to mentioned cloud computing and its need in our life. This document describes the categories of cloud services and its future scope. We all know the benefits of cloud and drawbacks also and future access within the world. And what all this will affect and how much will be the effect.

\section{REFERENCES}

[1] Arora Priyanka, Singh Arun, Tyagi Himanshu, (2012). . -Analysis of performance by using a security algorithm on cloud network, in an international conference on Emerging trends in engineering and management (ICETM2012), (pp. 179-180)

[2] Winkler, Vic. (2012)., "Cloud Computing: Virtual Cloud Security Concerns" in Technet Magazine, Microsoft, (pp. 40-42) 
[3] (2009) —"Swamp Computing" a.k.a. Cloud Computing". Web Security Journal, (pp. 494-498)

[4] Wik Philip, (2011-10), "Thunderclouds: Managing SOACloud Risk", in Service Technology Magazine, (pp. 494498)

[5] Hickey, Kathleen. (2012). "Dark Cloud: Study finds security risks in virtualization", in Government Security News, (pp. 40-42) 